\section{Hormone boosts attractiveness}

The hormone oxytocin may contribute to the romantic bonds that keep men faithful.

René Hurlemann at the University of Bonn, Germany, and his colleagues used functional magnetic resonance imaging to study the brains of two groups of 20 men. During the scans, one group looked at pictures of their female partners and unfamiliar women assessed by the researchers as being equally attractive, and the other group looked at photos of their partners and familiar women who were not relatives.

All 40 men rated their partners as more attractive than either unfamiliar or familiar women. But men who received nasal puffs of oxytocin before scanning gave higher ratings for their partners than did those who received a placebo. This boost occurred only with partners, and not with familiar women.

Men given oxytocin also had increased signalling in the reward centres of the brain when shown their partner's face, but not when shown a picture of a familiar woman. Proc. Natl Acad. Sci. USA http://doi.org/p74 (2013)

\section{CHEMISTRY}

\section{Catalysts on the cheap}

Chemists are making rapid progress in replacing catalysts that use precious metals, such as platinum and iridium, with catalytic molecules based on more abundant metals. Now, three groups have reported improved methods for adding hydrogen to particular parts of molecules - 'hydrogenation' reactions that are involved in making drugs, polymers and other industrial chemicals.

A team led by Paul Chirik at Princeton University in New Jersey studied catalysts that are based on simple cobalt salts wrapped by other widely available molecules. These are adept at hydrogenating a variety of carbon-carbon double bonds.

Robert Morris's group at the University of Toronto in Canada created iron-based catalysts that can hydrogenate carbon-oxygen or carbonnitrogen double bonds. Such catalysts are more active than commercial platinum compounds and are just as selective in producing the desired version of a compound.

And Matthias Beller at the University of Rostock in Germany and his colleagues found that catalysts using solid iron-oxide nanoparticles do well at hydrogenating another chemical structure, the aryl nitro group - useful in agrochemicals and dyes, for instance.

Science 342, 1073-1076;

1076-1080; 1080-1083 (2013)

\section{MOLECULAR BIOLOGY}

\section{RNAs leave yeast poised for action}

One way in which long, non-coding RNAs control gene expression in yeast is to accelerate the activation of protein-coding genes.

Elizabeth Tran and her colleagues at Purdue University in West Lafayette, Indiana, studied various strains of Saccharomyces cerevisiae, in which the $G A L$ genes are repressed or activated by different sugars in the environment. The team found that when these genes are released from a repressed state, long non-coding RNA molecules (lncRNAs) speed up GAL gene expression by quickly recruiting a key enzyme needed to make proteins. The lncRNAs also hinder the binding of molecules that repress $G A L$ genes.

The team suggests that these particular lncRNAs leave yeast poised and ready to quickly switch carbon sources in response to environmental changes.

PLoS Biol. 11, e1001715

(2013)

COMMUNITY CHOICE

The most viewed papers in science

VIROLOGY

\title{
Chinese origin for US pig virus
}

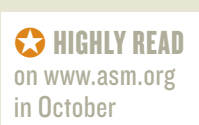

A mysterious pig virus outbreak that erupted in the United States in May 2013 was imported from China.

A team led by Xiang-Jin Meng and Yao-Wei Huang of Virginia Polytechnic Institute and State University in Blacksburg sequenced the genome of three US strains of porcine epidemic diarrhoea virus (PEDV), which has killed piglets at an alarming rate on hundreds of farms across the country.

The team found that these strains were similar to one found in Anhui province in China in 2010. Furthermore, one section of the PEDV genome is similar to that of a bat virus, suggesting that the pathogen can be transmitted between species. mBio 4, e00737-13 (2013)

\section{MATERIALS SCIENCE \\ Sticky surface switches on and off}

A magnetic material mimics the gravity-defying stickiness of a gecko's footpads and, notably, the creature's ability to turn this property on and off.

Researchers led by Aránzazu del Campo at the Max Planck Institute for Polymer Research in Mainz, Germany, created an adhesive surface made of arrays of T-shaped micropillars coated with neodymium magnet particles. Applying a magnetic field to this surface bent the pillars and quickly turned off its stickiness. The reversible system works in wet and dry conditions, and it can be easily prepared and scaled up, the authors say.

Adv. Mater. http://doi.org/p8m (2013)

\section{ZOOLOGY}

\section{Stealthy sea horse uses its head}

The long snout of the dwarf sea horse (Hippocampus zosterae; pictured) allows it to sneak up on its prey.

The creature sucks its victim into its mouth by quickly snapping its head upwards, but to do so it must get within one

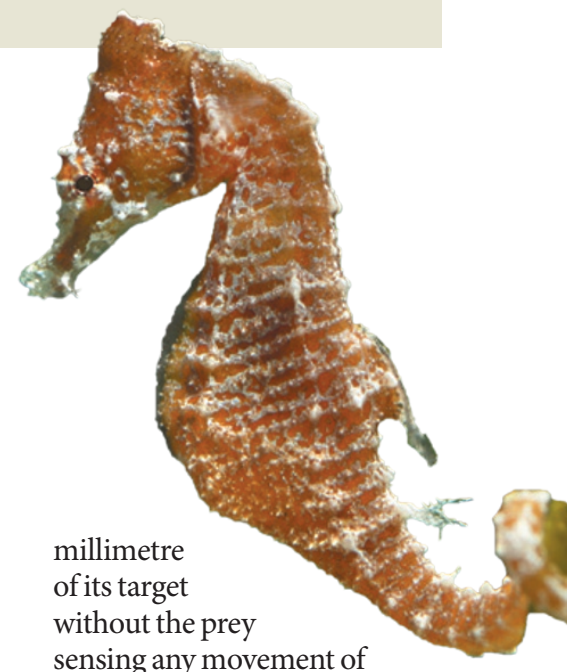

sensing any movement of the surrounding water.

A team led by Brad Gemmell at the University of Texas at Austin used three-dimensional digital holography to track the flow of water around a sea horse as it swam towards a small crustacean. They found that the unique shape of the sea horse's head, along with its orientation, creates a zone in which water is undisturbed as the sea horse moves.

The results could be relevant for the design of microfluidic devices that need to move water with minimal disturbances.

Nature Commun. 4, 2840 (2013)

\section{$\rightarrow$ NATURE.COM}

For the latest research published by Naturevisit:

www.nature.com/latestresearch 